\title{
A RETROSPECTIVE ANALYSIS OF THE COST-EFFECTIVENESS OF DENTAL SEALANTS IN A CHILDREN'S HEALTH CENTER*
}

\author{
Jane A. Weintraub, ${ }^{1}$ Sally C. Stearns, ${ }^{1}$ Brian A. Burt, ${ }^{2}$ Eugenio Beltran ${ }^{3}$ and \\ STEPHEN A. EKLUND ${ }^{2}$ \\ 'The University of North Carolina, School of Public Health, Department of Health Policy and \\ Administration, Campus Box 7400, Chapel Hill, NC 27599-7400, U.S.A., ${ }^{2}$ The University of Michigan, \\ School of Public Health, Program in Dental Public Health, Ann Arbor, MI 48109, U.S.A. and ${ }^{3}$ Centers \\ for Disease Control, Division of Oral Health, 1600 Clifton Road, MS F-10, Atlanta, GA 30333, U.S.A.
}

\begin{abstract}
A retrospective patient record analysis was conducted to study the cost-effectiveness of dental sealants placed under routine, unrestricted practice condition in a fluoridated community. The 26 dentists who provided care at the clinic over the period of the study used their own clinical judgement to determine sealant placement or alternative treatment. Dental services for 275 patients at a children's dental clinic for low-income families were evaluated. All children had at least 3 years between their first and last dental visit (mean $=5.8$ years). A lifetable analysis was conducted to compare the probability of survival (restoration-free tooth years) and costs incurred to first molars of children who did not receive sealants, received any sealants, or received sealants on all first molars. Among the children with sealants, comparisons were also made between sealed and unsealed teeth in children who did and did not have a first molar restoration prior to sealant placement. Costs included the cost of sealants and restorative treatments for these teeth over time. Depending on the conditions under which sealants were placed, cost-savings or improving cost-effectiveness with time were found. A strategy of identifying children with prior restorations and sealing the remaining molars showed cost-savings within 4-6 years. For other comparisons, incremental cost-effectiveness ratios became more favorable over time.
\end{abstract}

Key words - pit and fissure sealants, prevention, cost-effectiveness analysis, dental caries, health economics

\section{INTRODUCTION}

Widespread adoption of dental sealants has been slow because of lack of consumer and provider awareness, the relative absence of third party reimbursement, and uncertainty about the cost-effectiveness of the procedure $[1,2]$. Although many studies and reports have addressed the effectiveness of sealants [3] and the costs of sealants [4,5], the costeffectiveness of sealants has not been adequately resolved. Factors that affect the cost-effectiveness of sealants have been described by Mitchell and Murray [6], and Houpt and Shey [7]. These factors include: the caries prevalence of the community; the type and costs of the equipment, materials, and operator; the longevity of sealants and amalgams; the selection of patients and teeth to be sealed; and the use of other preventive methods. Results from thcoretical studics $[8,9]$, demonstration programs [10], and longitudinal studies with attrition rates resulting in small sample sizes [11] have various limitations. Study results are dependent on the assumptions made, the clinical conditions of use, or the characteristics of the participants. For example, Niessen and Douglass' [8] theoretical study made assumptions about caries

*This paper was presented, in part, at the 1989 AADR meeting in San Francisco. increment, the type of personnel applying sealant, sealant retention rates, the age of the children receiving sealant and the number of occlusal surfaces sealed per child. These assumptions may or may not reflect actual circumstances. Clinical trials and demonstration programs have control over certain variables such as patient and tooth selection, but do not reflect the variety of conditions and philosophies that exist in practice.

In studies in Minnesota [11,12] and New York [13], different study designs and conditions were used, and different conclusions were drawn. At the 10-year follow-up Simonsen [12] compared 12 matched pairs of patients, half initially with sealants on all four permanent first molars and half without sealants. The sealant group had all four first molars sealed at baseline. It was not reported why the control group of patients at the same health center had not received sealants. This study found application of sealants to lead to fewer restorations and a reduction in total costs compared to not using sealants. In contrast, the 4-year community clinical trial conducted in fluoridated Rochester, New York included 292 participants who had sealants placed on one side of their mouths on occlusal surfaces that were sound or had incipient carious lesions, and restorative treatment provided as needed on the other side. Caries rates were lower but costs were higher for the teeth receiv- 


$$
\begin{aligned}
& \mathrm{C}_{S}-\mathrm{C}_{\mathrm{NS}} \quad \mathrm{C}_{\mathrm{S}}=\text { cost of treatment in the sealant group } \\
& \overline{E_{S}}-E_{N S} \quad C_{N S}=\text { cost of treatment in the no sealant group }
\end{aligned}
$$

\begin{tabular}{|c|c|c|c|c|}
\hline Cost Savings & $\begin{array}{l}C_{S}<C_{N S} \\
E_{S}>E_{N S}\end{array}$ & Negative & Positive & Negative \\
\hline Cost-effectiveness & $\begin{array}{l}c_{S}>C_{N S} \\
E_{S}>E_{N S}\end{array}$ & Positive & Positive & Positive \\
\hline & $\begin{array}{l}C_{S}<C_{N S} \\
E_{S}<E_{N S}\end{array}$ & Negative & Negative & Positive \\
\hline Bad Investment & $\begin{array}{l}C_{S}>C_{N S} \\
E_{S}<E_{N S}\end{array}$ & Positive & Negative & Negative \\
\hline
\end{tabular}

INTERPRETATION RELATIONSHIP NUMERATOR DENOMINATOR VALUE OF CE RATIO

If the effects are the same, choose the lower cost approach. If the costs are the same, choose the more effective approach.

Fig. I. Incremental cost-effectiveness formula.

ing sealants. The investigators recommended that for sealants to achieve cost-savings, they should be used on persons who have demonstrated evidence of occlusal caries experience. Kuthy and colleagues [14] examined dental claims filed from a large insurance company for 419 matched pairs of children, one group that received sealants and one group that did not. Over the 39-month study period, the sealant group incurred a greater mean cost of $\$ 148$, and a mean time until a posterior restoration of about three months longer, than the no-sealant group. In 1986, recommendations regarding sealant use in the British General Dental Service were based, in part, on cost-effectiveness considerations [15]. Although sealants were acknowledged as being effective, sealants were not recommended as an item for reimbursement for sound, untreated teeth except for children deemed to be at special risk for dental disease.

The purpose of this study was to compare, under usual practice conditions, the cost-effectiveness of dental treatment with and without the inclusion of sealants among low-income children who were dental patients at the same health center over an extended period of time. The retrospective design required few assumptions compared to a hypothetical model since actual data were used. In addition the study conditions were more realistic than a demonstration program or clinical trial. However, the design does have limitations, which will be discussed.

\section{MATERIALS AND METHODS}

A retrospective patient record analysis was conducted to compare the treatment received by two groups of patients, one group (S) that received dental sealants, and one group (NS) that did not. The children were all treated at the Mott Children's Health Center (MCHC) for low-income children in Flint, Michigan, a community which has been fluoridated since 1967. The criteria for selecting children for the $\mathrm{S}$ group included receiving a sealant on at least one first permanent molar and, for both the S and NS groups, at least three years between the child's first and most recent dental visits at MCHC. From among all available dental records, those of 139 children satisfied the criteria for the $\mathrm{S}$ group. Subsequently, the NS group of 139 children was matched to the S group by the age distribution of the children at their first dental visit which may have been before or after the first molar erupted. Since this study was a retrospective one, criteria for placing or not placing sealants were determined individually by each of the 26 dentists who treated children during the time period under study. Therefore, children were not randomly assigned to a sealant or no-sealant treatment regimen.

Tooth-level data were analyzed since sealant use and outcomes (restorations) occur at the tooth level. However, the primary analytical approach was to compare teeth of children grouped according to whether the child received any sealants. This ap- 
Table 1. Demographic characteristics and dental utilization of the 275 children by sealant (S) and no sealant (NS) treatment group

\begin{tabular}{lcccc}
\hline Characteristic & $\begin{array}{c}\text { S group } \\
n=139\end{array}$ & $\begin{array}{c}\text { NS group } \\
n=136\end{array}$ & $\begin{array}{c}\text { Total } \\
n=275\end{array}$ & $P *$ \\
\hline Gender-\% female & 55 & 48 & 51 & 0.254 \\
Medicaid-\% eligible & 51 & 40 & 46 & 0.077 \\
Mean age (SD) at first visit & $7.38(2.3)$ & $7.37(2.3)$ & $7.37(2.3)$ & 0.982 \\
Mean (SD) number of: & & & & \\
$\quad$ Years between first & $5.6(1.6)$ & $5.9(1.5)$ & $5.8(1.5)$ & 0.101 \\
$\quad$ and last visit & $14.9(6.1)$ & $14.6(6.0)$ & $14.8(6.0)$ & 0.722 \\
Dental visits & $7.9(2.9)$ & $8.6(3.0)$ & $8.3(3.0)$ & 0.041 \\
Dental exams & $7.4(2.9)$ & $7.9(3.2)$ & $7.6(3.1)$ & 0.169 \\
Fluoride treatments & $7.9(2.9)$ & $8.5(3.1)$ & $8.2(3.0)$ & 0.077 \\
Dental prophylaxis & $3.7(4.4)$ & $2.9(3.7)$ & $3.3(4.1)$ & 0.116 \\
$\quad$ Primary tooth restorations & & & & \\
\hline $\boldsymbol{P}$ values determined by Student $t$-test for comparison of means or $\chi^{2}$ test for comparison of
\end{tabular}
proportions.

proach was chosen for three reasons. First, policies apply to children rather than individual teeth. Second, all teeth within an individual's mouth are affected by many of the same factors such as diet, fluoride, oral hygiene, and systemic conditions. Third, dentists consider both tooth and person-level characteristics when determining treatment.

In addition to demographic information including age, gender, and Medicaid status, the date and type of sealants and restorations rendered to the first permanent molars, as well as provision of other preventive services, were obtained from the dental records. In addition to the written records, the tooth charts, drawings of the existing tooth conditions, were examined to determine, when possible, if the first molars had been restored prior to the first visit. The occlusal surfaces were assumed to be sound and restoration-free if sealed or unrestored at the child's last dental visit. To calculate the length of time that a first molar remained sound, it was also assumed that the first molars erupted at the child's sixth birthday. Effects were measured as the number of years the tooth remained restoration-free from the sixth birthday until each child's last visit.

Costs were calculated for restorations and sealants by using the 1985 American Dental Association median fee schedule [16]. According to this fee schedule, the charges were $\$ 12$ for a sealant, $\$ 25$ for a one-surface amalgam, and higher charges for other restorative services or extractions. The analyses were performed without discounting as well as using a 5\% rate to discount costs and benefits [17] to the present value at the time of the child's sixth birthday.

A lifetable analysis [18] was used to evaluate the probability of each first molar 'surviving' without an occlusal restoration to the end of each interval given that it survived restoration-free to the beginning of the interval, as well as to calculate the costs incurred during the observation period. Because the child's dental treatment was observed for at least three years and because some children's dental records were available for up to 11 years, analysis of annual intervals was chosen as the most useful period for analysis. The lifetable analysis accounts for censoring of data that occurs because not all children are observed for the same length of time. Each molar was at risk of decay either until a molar restoration was placed or for as long as the child was observed. Each molar was at risk of costs (sealant or restoration costs) for as long as the child was observed, since costs may continue to accrue to a tooth once it has initially decayed as restorations are replaced. Each molar for each child was considered to be censored (for costs, and for decay if it had not yet been restored) at the end of the child's observation period.

Since most children were not viewed for an exact number of years, it was necessary to either use a lifetable analysis method that excluded information for the last partial year that the child was observed, or to utilize some method to account for the partial last year properly [18]. In this lifetable analysis, partial years were excluded from the calculations. Although this approach meant that some information was not used in the lifetable analysis, it avoided the use of arbitrary assumptions about whether or not teeth only observed for a final partial year were likely to decay by the end of the year. The probability of a tooth decaying in a single period, given survival up to the start of the period, was calculated simply as the number of 'deaths' (i.e. teeth that decayed) during the time period divided by the total number of teeth at risk at the start of the time period.

Next, an incremental cost-effectiveness analysis was conducted comparing children in the NS group with children in the $S$ group as well as with the subset of children who received sealants on all four first permanent molars. Children who had all four first molars sealed would have the opportunity to derive the maximum benefit from the procedure. For successive years of observation, the cumulative differences in cost per tooth were divided by the cumulative differences in expected restoration-free tooth years to derive cost-effectiveness ratios for different lengths of time. Figure 1 provides the formula used and indicates the different outcomes that may result from the incremental cost-effectiveness analysis. Specifically, if sealants lead to a reduction in total costs and have at least as good or better effects (i.e. as many or more restoration-free tooth years), then use of sealants would lead to cost-savings, and a clear recommen- 
Table 2. Results for first permanent molars by children and treatment group

\begin{tabular}{|c|c|c|}
\hline $\begin{array}{l}\text { Treatment characteristics } \\
\text { of children }\end{array}$ & $\begin{array}{c}\text { S group } \\
\text { (No. children) }\end{array}$ & $\begin{array}{l}\text { NS group } \\
\text { (No. children) }\end{array}$ \\
\hline Number of children & 139 & 136 \\
\hline Number of sound molars at first visit & 542 & 522 \\
\hline Mean number of sealants/child & 3.7 & NA \\
\hline Mean number of teeth sealed/child & 3.0 & $\mathrm{NA}$ \\
\hline $\begin{array}{l}\text { Percentage of children with } \\
\text { restorations }\end{array}$ & $50(n=69)$ & $48(n=65)$ \\
\hline Mean number of restorations $s^{2} /$ child & 1.2 & 1.6 \\
\hline $\begin{array}{l}\text { Mean number of restorations } \\
\text { child with restorations }\end{array}$ & $2.4(n=69)$ & $3.3(n=65)$ \\
\hline $\begin{array}{l}\text { Among children with restorations } \\
\text { percentage of their first molars restored }\end{array}$ & 52 & 63 \\
\hline
\end{tabular}

dation can be made for their use. However, if sealants lead to higher costs and better effects, then sealants are cost-effective in the sense that one pays for something and gets something in return. If this occurs, it is up to the payor to decide whether the effects (i.e. the additional restoration-free tooth years) from the sealants are worth what they cost. A situation in which sealants resulted in worse effects (i.e. more restorations) and lower costs relative to non-sealant use would result in the situation of non-sealant use being cost-effective relevant to sealant use. Finally, if sealants result in a situation in which costs are higher and effects are the same or worse (i.e. as many or fewer restoration-free tooth years), then sealants would be a bad investment. Mathematically, the value of the cost-effectiveness ratio will be negative under scenarios of both costsavings and bad investments. Therefore, in interpreting the graphs of the results, it is important to distinguish between curves that become negative (i.e. are below the $x$-axis) for different reasons.

In addition to comparisons between children receiving no sealants, any sealants, or sealants on all four molars, the children who received any sealants were divided into two groups: those who received a first permanent molar restoration either before, during, or within one month of their first sealant; and those who did not. Comparisons of these groups can be useful in assessing the cost-effectiveness of the alternative strategies of sealing teeth after evidence of dental caries occurs in the first permanent molars to the cost-effectiveness of sealing teeth prior to evidence

Table 3. Number of children by number of years observed" and sealant status

\begin{tabular}{cccc}
\hline Year & No sealant & Any sealant & Four molars sealed \\
\hline 1 & 136 & 139 & 71 \\
2 & 136 & 139 & 71 \\
3 & 133 & 137 & 70 \\
4 & 128 & 135 & 69 \\
5 & 117 & 112 & 54 \\
6 & 91 & 90 & 39 \\
7 & 67 & 63 & 27 \\
8 & 52 & 39 & 16 \\
9 & 35 & 25 & 12 \\
10 & 19 & 13 & 6 \\
11 & 9 & 4 & 2 \\
\hline
\end{tabular}

${ }^{a}$ From sixth birthday of dental caries in the first permanent molars. Given the non-experimental nature of the study, this comparison offers an assessment of the potential costeffectiveness of sealants, particularly in situations in which decay on at least one molar is used as an indication of the need for sealants on other molars

\section{RESULTS}

Although 139 children were initially selected for each group, not all of the teeth were suitable for sealants. Specifically, at the time of their first visit in the clinic, some children had first molars that had already been restored or had sufficient decay that they were restored during or within a short period following the first visit. These teeth (14 in the $S$ group and 34 in the NS group) were excluded from the analysis. Three children in the non-sealant group had all four first molars excluded and were dropped from subsequent analysis.

Characteristics of the children in each group are presented in Table 1. The mean time interval between the first and most recent dental visit at $\mathrm{MCHC}$ was 5.8 years. There were no significant differences between groups with respect to mean age at first visit or gender distribution. Although not statistically significant at the $P=0.05$ level, the NS group did have a longer mean time interval between first and most recent visit, and more dental prophylaxes and fluoride treatments, while the $S$ group had more dental treatment on primary teeth and consisted of a larger proportion of Medicaid eligible children. Although the number of visits was similar, the $\mathbf{S}$ group had significantly fewer dental exams than the NS group, perhaps because the visits were made to restore the primary teeth. These differences are consistent with the possibility that dentists may be more likely to use sealants in children who they perceive are at greater risk of decay or who are less frequent users of preventive dental exams and services. The statistical tests used to compare the distribution of these characteristics between the groups do not assess or control for the effects of confounding or indicate how these factors might influence the association between use of sealants and resulting costs or restorations [19]. 
Table 4. Lifetable analysis ${ }^{\mathrm{a}}$ of teeth of children with no sealants, children with any sealant, and children with four first molars sealed

\begin{tabular}{|c|c|c|c|c|c|c|}
\hline \multirow[b]{3}{*}{$\begin{array}{l}\text { Total } \\
\text { years }^{b}\end{array}$} & \multicolumn{6}{|c|}{ Teeth of children with: } \\
\hline & \multicolumn{2}{|c|}{ No sealants } & \multicolumn{2}{|c|}{ Any sealants } & \multicolumn{2}{|c|}{ Four molars sealed } \\
\hline & $\begin{array}{l}\text { Cumulative } \\
\text { years of } \\
\text { survival }\end{array}$ & $\begin{array}{l}\text { Cumulative } \\
\text { cost per } \\
\text { tooth }\end{array}$ & $\begin{array}{c}\text { Cumulative } \\
\text { years of } \\
\text { survival }\end{array}$ & $\begin{array}{l}\text { Cumulative } \\
\text { cost per } \\
\text { tooth }\end{array}$ & $\begin{array}{l}\text { Cumulative } \\
\text { years of } \\
\text { survival }\end{array}$ & $\begin{array}{l}\text { Cumulative } \\
\text { cost per } \\
\text { tooth }\end{array}$ \\
\hline 1 & 0.99 & 0.28 & 0.97 & 1.64 & 1.00 & 1.14 \\
\hline 2 & 1.92 & 1.02 & 1.88 & 4.58 & 1.95 & 4.85 \\
\hline 3 & 2.75 & 2.62 & 2.69 & 7.78 & 2.84 & 7.10 \\
\hline 4 & 3.51 & 3.69 & 3.42 & 10.54 & 3.69 & 9.17 \\
\hline 5 & 4.19 & 5.41 & 4.09 & 12.83 & 4.48 & 11.25 \\
\hline 6 & 4.79 & 6.97 & 4.69 & 15.29 & 5.24 & 12.69 \\
\hline 7 & 5.31 & 9.01 & 5.25 & 17.24 & 5.96 & 15.18 \\
\hline 8 & 5.80 & 9.81 & 5.76 & 18.27 & 6.64 & 15.31 \\
\hline 9 & 6.24 & 10.25 & 6.24 & 19.30 & 7.30 & 16.50 \\
\hline 10 & 6.65 & 11.79 & 6.70 & 19.93 & 7.92 & 17.79 \\
\hline 11 & 7.03 & 11.79 & 7.13 & 19.93 & 8.51 & 17.79 \\
\hline
\end{tabular}

${ }^{a}$ Years of survival and costs were both discounted using an annual rate of $5 \%$.

'Years following child's sixth birthday.

However, the tests do assess the extent to which the matching of the two groups was successful for the criteria used.

Table 2 presents first permanent molar treatment characteristics for children remaining in each group. The children in the S group had 519 sealants placed on $414(76 \%)$ of their 542 unrestored first permanent molars. About half of the children in each group had occlusal surfaces restored between their first and last visit, $50 \%$ for the $\mathrm{S}$ group and $48 \%$ for the NS group. Although this proportion is slightly higher for the $S$ group, the mean number of first molar restorations involving the occlusal surface per child (FMOR) was lower for the $S$ group than the NS group. Sixty-nine children in the $S$ group received 164 FMOR on 140 molars, while 65 in the NS group received 213 FMOR on 154 molars. About a third of the children in the sealant group had received a FMOR prior to receiving a sealant.

Additional descriptive comparisons may be made considering the first molar as the unit of analysis. In the NS group, 59 of the 154 molars that were restored were restored at least twice. Of the 41 sealed teeth that were restored, 16 received a two-surface restoration, and 24 teeth were restored at least twice. One-fourth of the sealed teeth were sealed more than once.

While the above comparisons are interesting, they are aggregate comparisons using data for children who were observed for different lengths of time. A more precise analysis and set of comparisons can be made, therefore, by using a lifetable analysis that looks at the cumulative years without restoration and the cumulative costs of treatment (sealant and restoration costs) for each year following the child's sixth birthday until a maximum of 11 years.

Table 3 shows the number of children in each of the three groups (no sealant, any sealant, or four first molars sealed) over the 11-year observation period. At least half of the children in each group were followed for at least 6 years, though few were followed for 11 years. About half of the children who received any sealants had all four first permanent molars sealed. Thus, the data for the 'Any Sealant' group reflects the composite results for several groups of children with different types of sealant experience. Table 4 shows the cumulative restoration-free years of survival and cumulative costs for the molar teeth of children in each group. Since not all sealants were placed at the initial visit, the cumulative average costs for children who ultimately received sealants on each molar is very low during the first year. As more of the sealants were placed, the cumulative costs increased substantially over the next two to three years for this group relative to the no sealant group. Figure 2 illustrates the survival probabilities for each time period. The teeth of children with four molars sealed had the greatest probability, both cumulatively and for each year. However, Table 4 shows that the cumulative cost per tooth was least expensive each year for children who did not receive sealants.

Incremental cost-effectiveness (CE) comparisons for these three groups of children (no-sealant, any sealant, and all four molars sealed) are shown in Fig. 3. Restoration-free years and costs are both discounted at $5 \%$. The incremental cost-effectiveness for children with four first molars sealed versus children without sealants steadily became more favorable with time so that, after 11 years, the incremental CE ratio was $\$ 4.06$ per additional welltooth year. The incremental CE ratio was $\$ 3.16$ if no discounting was used. These estimates are based on cumulative information over time involving all the children in these groups for the time they were observed. As shown in Table 3, few children were observed for the full 11 years, and the values for the last few years are affected by increasingly smaller samples and should be interpreted cautiously. When comparing children with no scalants to those with any, the incremental $\mathrm{CE}$ ratio was unfavorable (children with sealants incurring higher costs and fewer years of tooth survival) until the tenth year of observation beyond the sixth birthday. (Ninth-year data are not graphed because the cumulative years of 


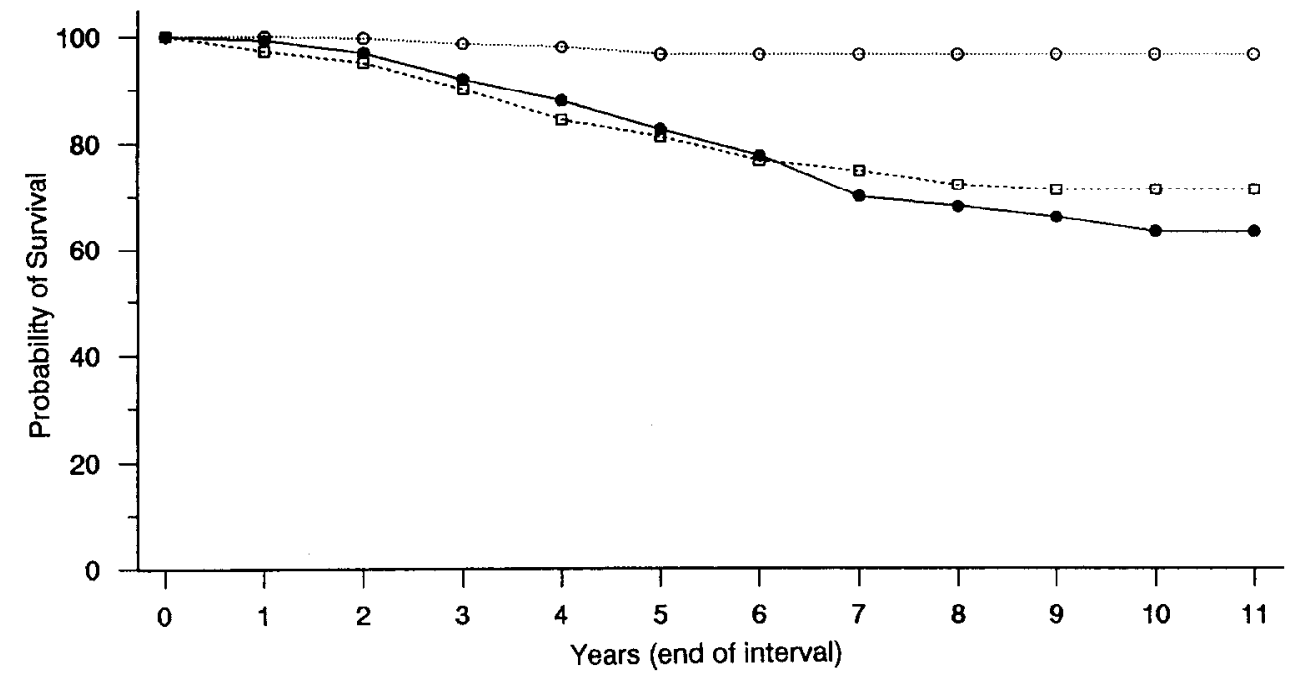

\section{No Sealants Any Sealants Four Molars Sealed}

Fig. 2. Survival probability $\times 100$ for teeth of children with no sealant, any sealants or four first molars sealed.

tooth survival are virtually the same, leading to a zero in the denominator of the $\mathrm{CE}$ ratio as sealants go through a transition from being a bad investment to a cost-effective treatment. The non-sealant approach would be preferred because of the lower cumulative costs.) The 11-year incremental CE was $\$ 81.96$ per additional restoration-free tooth year using the $5 \%$ discount rate and $\$ 47.12$ with no discounting. Although these incremental amounts are relatively high, the use of sealants appeared to be cost-effective by the tenth year, with cost-effectiveness improving in the eleventh year.

Since the first molars of the children in the Any Sealant group are a mixture of sealed and unsealed teeth, comparisons of the experiences of these teeth according to sealant status can be made. Restorationfree survival curves for the four groups of teeth (103 sealed and 31 unsealed teeth for the 53 children who received sealants after a prior first permanent molar restoration, and 311 sealed and 33 unsealed teeth for the 83 children who received sealants prior to having any molars restored) are shown in Fig. 4 . The sealed teeth had a higher survival probability than the unsealed teeth regardless of the child's prior restoration status. The unsealed teeth in the children who had prior restorations had the worst survival probability. In the eighth year the number of teeth in children without prior restorations with and without sealants were 68 and 4 , and in children with prior restorations with and without sealants were 40 and 12 respectively. Comparisons beyond eight years are not provided because one of the unsealed teeth groups has fewer than four teeth available for analysis. As in the earlier analysis, the number of children, and therefore teeth, observed in later years decreases, and values from the later years should be interpreted cautiously. In the groups with and without prior restorations, the sealed teeth had much greater 8 -year survival, 85 and $94 \%$, than the unsealed teeth, 23 and $46 \%$, respectively. Figure 5 illustrates the incremental cost-effectiveness analysis for the sealed and unsealed teeth in these two groups up to 8 years. For the children with prior restorations, cost-savings were achieved after approximately 4-6 years. For the children without prior restorations, cost-savings were achieved after 8 years.

Table 5 summarizes the findings at the end of the four years of observation for the different comparisons. Although the earlier analyses presented findings for as many years as the data allowed, the fourth year represents a trade-off between using as large a sample as possible while still following the children far enough to observe the trends and short-run implications of sealants with respect to cost-effectiveness and cost-savings. In the fourth year, the results were based on at least 23 or more teeth, yet patterns of cost-effectiveness that continue for the next several years are established. When comparing the children who received any sealants to those who received none, providing sealants was not shown to be a good investment in the short term. However, when two additional aspects of the situation are considered, this observation is modified. First, if the group of children who did not receive sealants are compared to those who received sealants on all first molars, the choice to seal is cost-effective, but relatively expensive at $\$ 28.86$ per restoration-free year. Second, and perhaps more important, the comparison of the no-sealant group (Group A) to the any sealant group (Group B) may be biased if dentists were, 


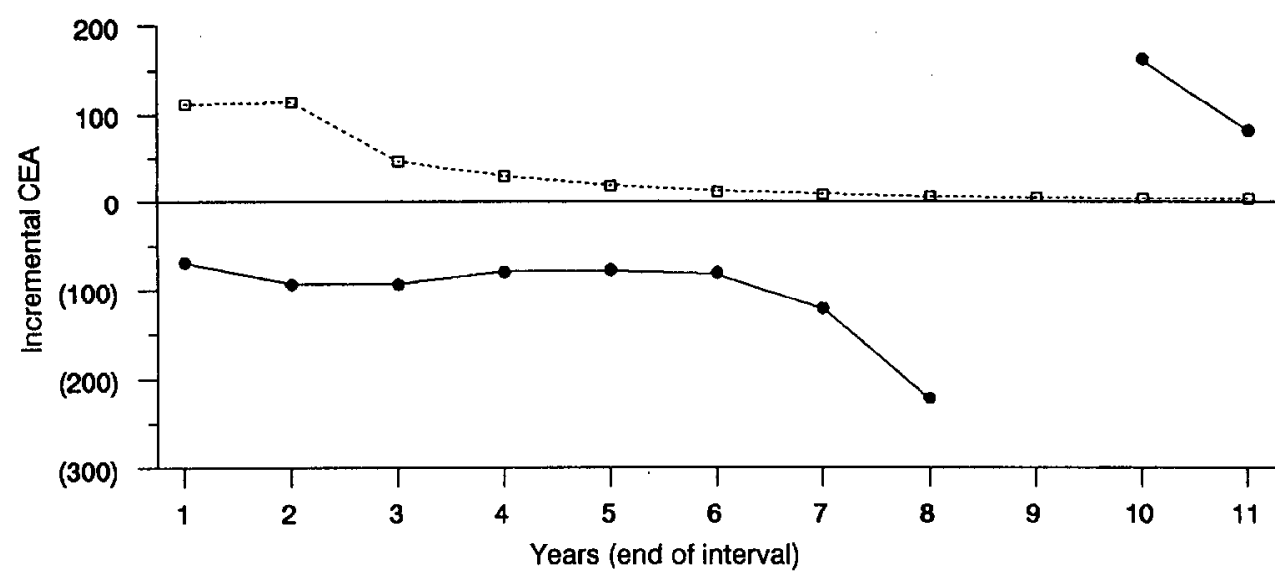

\begin{abstract}
No Sealants No Sealants
vs. Any Sealants vs. 4 Molars Sealed ..........

Note: Years of survival and costs were both discounted using an annual rate of $5 \%$. The graph for No Sealants vs. Any Sealants is discontinuous in the 9th year. See text for dlscussion.
\end{abstract}

Fig. 3. Incremental cost-effectiveness analysis for teeth of children with no sealants vs any sealants, and no sealants vs four first molars sealed.

at least to some extent, more likely to put sealants on molars of children at higher risk of decay (either with or without prior restorations). In particular, the costs and benefits accrued to the children in the Group B reflect a mixture of sealed and unsealed teeth that are part of Groups D G (as well as the teeth with prior restorations that were excluded from Groups D and E for analysis). Cost-savings occurred within 4-6 years if a child's teeth were sealed after the child had already received a first molar restoration, based on comparisons of sealed and unsealed teeth in these children. If sealants were placed prior to any molar restorations, the 4-year cost-effectiveness was $\$ 10.26$ per additional restoration-free year.

\section{DISCUSSION}

This study provides an empirical analysis of the cost-effectiveness of sealants. Although the study was not designed to study sealant effectiveness, the vast majority of sealed tooth surfaces did not receive restorative treatment over the time period of the study. For sealants to remain effective, they need to be repaired or replaced as needed. During the observation period, $25 \%$ of the sealants were replaced. Over time, restorations also need to be replaced. In the $\mathrm{S}$ and NS groups, 4 and $11 \%$ of teeth respectively were restored at least twice.

Based on anecdotal information, it was expected that the dentists at the MCHC would fall into two categories - those who routinely applied sealant to their patients' teeth, and those who did not. Of the 26 dentists who practiced at the MCHC during this time period, 20 had treated the children in the $S$ group and
15 had treated children in the NS group. An overlap of dentists between groups implies that they were using some type of criteria for selecting children to receive sealants. Because of the non-randomized nature of this study, the dentists' selection criteria could have introduced bias into the results. The dentists were not interviewed on their treatment planning philosophies, preventive orientation, or criteria for sealant use.

Thus, unlike a randomized clinical trial, the basis upon which the dentists decided to seal, restore, or watch any particular tooth was unknown and uncontrolled. An experimental design that randomly assigned children to $\mathrm{S}$ and NS groups prior to the eruption of their first permanent molars would be easier to interpret and provide stronger scientific evidence of the relative cost-effectiveness of dental sealants but would be less generalizable to actual dental practice. In addition, given the current knowledge of sealant effectiveness, it might be considered unethical to conduct an experimental study that would intentionally withhold sealants from some children. It is possible, however, to speculate on the direction of bias that may have been introduced by the non-randomized design. For example, it is conceivable that dentists may have chosen to seal teeth perceived to be at relatively higher risk of decay than those not sealed. In this case, a more appropriate control group for comparison to the persons receiving sealants would have had higher rates of caries, restorations, and costs than did the NS group used for comparison in this study. Therefore, the results on the cost-effectiveness and potential cost-savings from sealants may be underestimated. In the unlikely scen- 

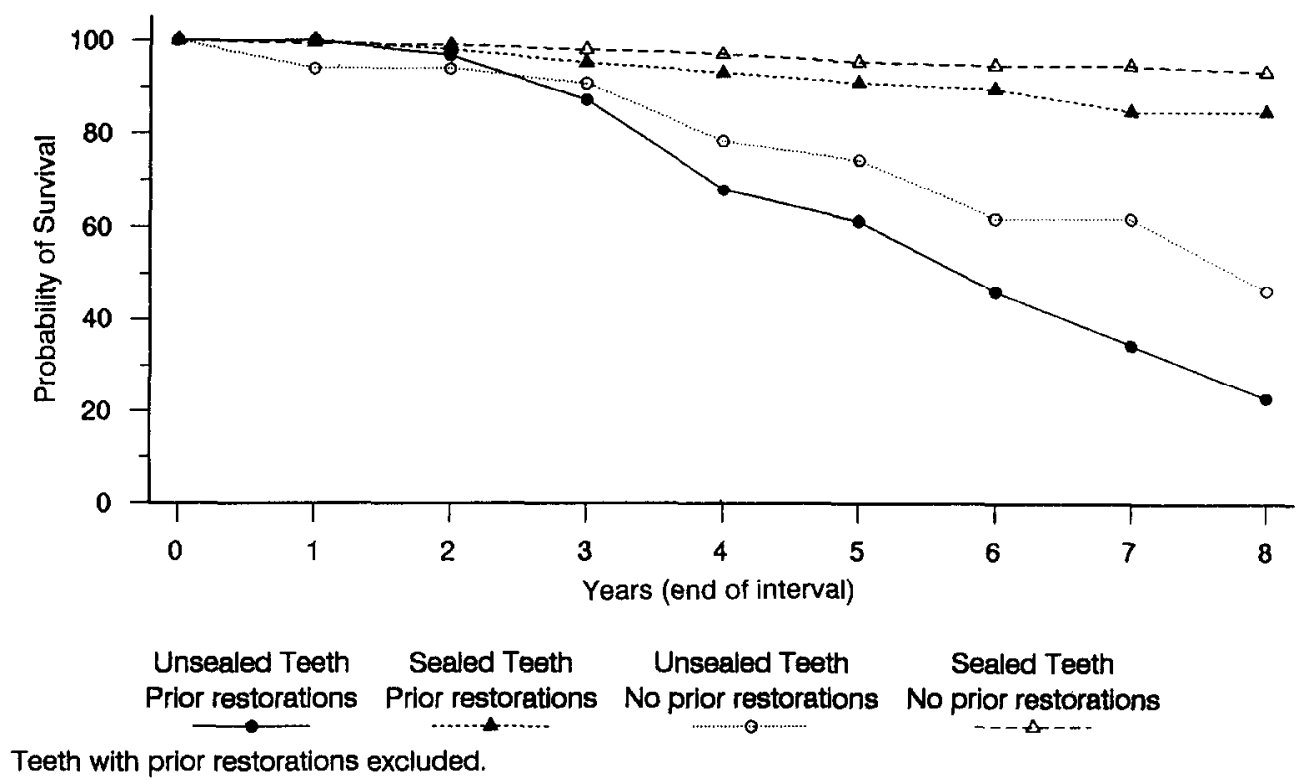

Fig. 4. Survival probability $\times 100$ for teeth of children who did and did not receive a restoration before receiving a sealant by molar sealant status.

ario in which dentists selectively seal teeth that are at lower risk of decay, the cost-effectiveness would be over-estimated. However, if dentists are not able to accurately predict which teeth are more likely to decay, or if dentists choose to seal teeth based on factors unrelated to caries risk, then the decision to seal would approach a random choice, and the samples chosen for this study might simulate random assignment of children to sealant and non-sealant groups.

Some criteria used for sealant placement can be hypothesized. Because the children in the $S$ group were more likely to be Medicaid-eligible, and had received more restorative dental treatment on primary teeth than the children in the NS group, the dentists may have used these factors to select children to receive sealants. It should be noted that in this study Medicaid status was determined only at one point, although all the families were lowincome and may change their status over time [20]. Table 5 shows that the expected total years of survival of unsealed teeth in the $\mathrm{S}$ group is less favorable than that of the NS group, indicating that the children who received sealants may have been more caries-prone or seen by dentists more apt to restore incipient lesions than the NS children. During this time period, it was unlikely that the dentists at MCHC were intentionally sealing incipient lesions. Teeth with incipient lesions could not be identified in this study. If incipient lesions had been sealed instead of restored, the total treatment costs would have been lower. The cost-effectiveness of sealing incipient lesions could not be tested here, though the philosophical basis for sealing incipient lesions, i.e. sealing susceptible teeth, is close to that for sealing in chil- dren with prior restorations, which was examined in this study.

As demonstrated by Eklund [21], the potential cost-savings for sealing teeth compared to not sealing them improve as the charges for sealants decrease relative to the charges for a restoration. Based on the observed patterns of sealant use and restorative treatment, similar improvements in the cost-effectiveness ratios calculated in this study would occur under an assumption of lower relative charges for sealants. Also, extrapolations of the effect of sealants over a longer period of time could be made using assumptions about relative rates of new and replacement restorations between groups, rates of sealant placement and replacement, and rates of subsequent treatment costs. Although the time period after eruption has been traditionally thought of as being the most caries-prone period, recent data [22] indicate that teenagers may be as susceptible to occlusal carious lesions as children. However, the data available for this study only allowed estimation through age 17 , and the estimations for the eighth through eleventh year after the sixth birthday (ages 14-17) are based on fairly small sample sizes for the $\mathrm{S}$ and NS comparison, and can not be made for the comparisons of sealed and non-sealed teeth by prior restoration status.

Policy makers are often likely to consider the short-term cost-effectiveness when deciding whether or not to implement a sealant program. Cost-effectiveness calculations of the short-run effects of preventive procedures are often not favorable because the costs of preventive procedures occur immediately, whereas the costs of not undertaking prevention are delayed to a future period. However, results 


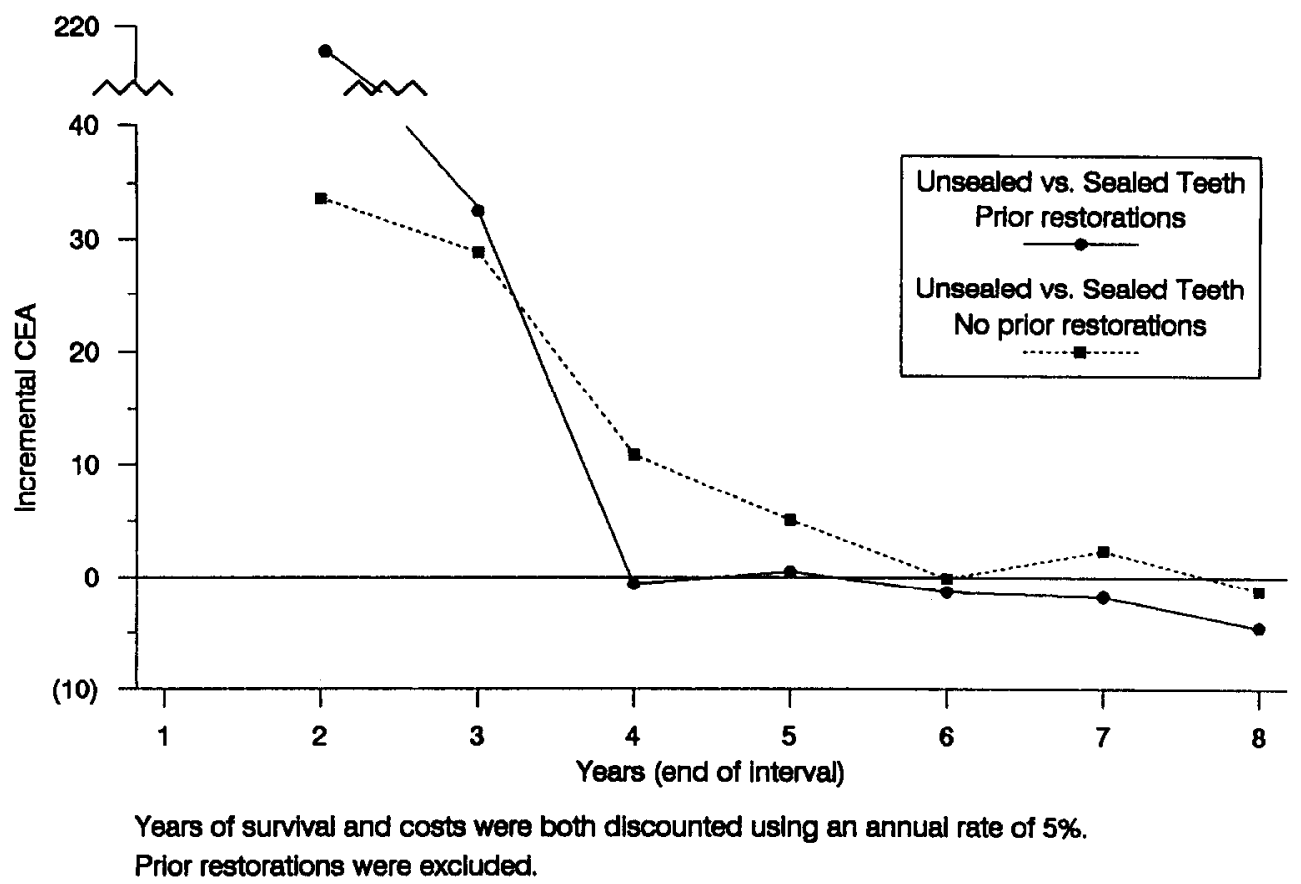

Fig. 5. Incremental cost-effectiveness analysis for teeth of children with sealants by prior restoration status.

from this study show cost-savings within 4-6 years from a strategy of identifying children with prior restorations (presumably due to prior evidence of caries) and sealing the remaining molars. Furthermore, incremental cost-effectiveness ratios became more favorable over time for all the comparisons, and studies with longer follow-up periods might show cost-savings from general application of sealants. These cost-savings would occur, for example, if: (1) the use of sealants keep teeth from decaying during adolescent years; (2) restorations rates are relatively low in unrestored teeth in subsequent adult years (so that continuous replacements of sealants over one's lifetime is not required); and (3) replacements of restorations that occur in the absence of sealants are required. If methods with high sensitivity and specificity for identifying children at high caries risk (ideally before caries occur) are developed, the use of sealants for these children could result in further cost-savings. Similarly, it is possible that the cost-effectiveness or cost-savings potential of sealants could be improved if criteria were developed and used to identify and target low caries-prone children and to withhold or postpone sealant placement among children whose molars, in the short term, are likely to remain cariesfree without the protection of sealants.

At the time that this study was designed, the $\mathrm{MCHC}$ was selected for a variety of reasons. The $\mathrm{MCHC}$ has a patient population with a low socioeconomic status similar to other dental public health programs. Although $\mathrm{MCHC}$ is in a fluoridated area, it was expected that these children would have a higher than average caries susceptibility. Relatively little treatment for dental caries was needed by either the $\mathrm{S}$ or the NS group. The children in both groups, however, were frequent dental utilizers (in part because of the study selection criteria) and had extensive exposure to preventive dentistry including community water fluoridation, topical fluoride treatments, and dental prophylaxis. In this type of comparison, sealants might have been more cost-effective, or cost-savings could have been achieved sooner if the study population did not have access or exposure to these other caries preventive measures. In this era of caries decline, knowledge of the occlusal caries rates in a community is especially important before implementing a sealant program. The lower that a community's caries incidence becomes, the less cost-effective are sealants likely to be with regular use.

As discussed by Warner [17], cost-effectiveness analysis is a 'decision-assisting' technique. In this analysis the benefits and costs of a sealant program were viewed from the perspective of whoever will pay for the dental care, either the consumer paying for dental treatment out-of-pocket or a public clinic administrator paying from a limited budget. In making a decision about whether to utilize dental sealants, either on an individual basis or as part of a public health program, other factors besides costs must be considered. These factors may involve value judgements and quality of life considerations that are not easily quantifiable. For example, if the clinician, the parent, the patient, or the policy-maker thought that maintaining a sound tooth was worth the ad- 
Table 5. Summary statistics at the end of year 4

\begin{tabular}{|c|c|c|c|c|c|c|}
\hline & Group & $\begin{array}{l}\text { Teeth } \\
\text { at risk }\end{array}$ & $\begin{array}{l}\text { Expected years of } \\
\text { survival/tooth }\end{array}$ & $\begin{array}{l}\text { Cumulative } \\
\text { cost }\end{array}$ & $\begin{array}{c}\text { Incremental } \\
\text { cost-effectiveness }\end{array}$ & Conclusion \\
\hline No sealants & A & 446 & 3.76 & 4.06 & & \\
\hline Any sealants & $\mathbf{B}$ & 439 & 3.67 & 11.46 & $\begin{array}{l}\text { A vs B } \\
-79.31 \\
\text { A vs C }\end{array}$ & Bad investment \\
\hline 4 molars sealed & $\mathrm{C}$ & 220 & 3.96 & 9.91 & 28.86 & Cost-effective \\
\hline \multicolumn{7}{|c|}{$\begin{array}{lcccc}\text { Among children in Group B with restorations prior to sealant placement: } \\
\text { Unsealed teeth } & \text { D } & 29 & 3.52 & 10.32\end{array}$} \\
\hline Sealed teeth & $\mathrm{E}$ & 89 & 3.86 & 9.73 & $\begin{array}{l}\text { D vs E } \\
-1.70\end{array}$ & Cost savings \\
\hline \multicolumn{6}{|c|}{ Among children in Group B with no prior restorations: } & \\
\hline Scalcd tecth & $\mathrm{G}$ & 241 & 3.94 & 10.26 & $\begin{array}{r}F \text { vs } G \\
10.24\end{array}$ & Cost-cffective \\
\hline
\end{tabular}

No discounting was used.

ditional cost of applying sealant, then he or she would choose to do so. If the comparisons were being made between use of sealants and amalgams for treating incipient lesions, the cost-effectiveness for sealants would be more favorable than in this study where use of a sealant procedure is being compared to the alternative of no procedure.

In summary, while the results from the study are subject to sample size limitations and possible biases from the non-randomized design, they are based on real program experience and provide plausible evidence of beneficial effects from sealants in both a long and short term perspective. The long-term trends in reduced cost per additional restoration-free tooth year over time are consistent with an ultimate outcome of cost-savings from sealants. The trend toward cost-savings occurred sooner for the group with all four first molars sealed. In the short-term, cost-savings within 4-6 years are not expected except among children who have already had first permanent molar restorations. Given limitations on resources, these children should be given the highest priority for sealant placement. In addition, a universal sealant policy may be supported either if it is deemed that the value of restoration-free tooth years exceeds the estimated cost per restoration-frec ycar or if stronger evidence of cost-savings is provided from studies with longer follow-up periods.

Acknowledgements - This study could not have been conducted without the support and cooperation of the Mott Children's Health Center in Flint, Michigan. Special appreciation is expressed to Dr Fred Bruner, Dental Director, for his continued interest and encouragement with this research project and his dedication to preventive dentistry and the children in the community. We would also like to thank Dr Gary Rozier and Dr James Bader for their critical review and comments on drafts of this manuscript.

This study was supported by the Michigan Department of Public Health

\section{REFERENCES}

1. Gift H. C. and Frew R. A. American Dental Association Health Foundation. Sealants: changing patterns J. Am. Dent. Assoc. 112, 391-392, 1986.
2. Cohen L., LaBelle A. and Romberg E. The use of pit and fissure sealants in private practice: a national survey. J. publ. Hlth Dent. 48, 26 35, 1988.

3. Weintraub J. A. The effectiveness of pit and fissure sealants. J. publ. Hlth Dent. 49, 317-320, 1989.

4. Garcia A. I. Caries incidence and costs of prevention programs. J. publ. Hlth Dent. 49, 259-271. 1989.

5. Foch C. B. et al. Cost of Treatment Procedures in the National Preventive Dentistry Demonstration Program. Rand Corporation, Santa Monica, 1984.

6. Mitchell L. and Murray J. J. Fissure sealants: a critique of their cost-effectiveness. Community Dent. oral Epidemiol. 17, 19.23, 1989.

7. Houpt M. I. and Shey Z. Cost-effectiveness of tissure sealants. J. Dent. Children 50, 210-212, 1983.

8. Niessen L. C. and Douglass C. W. Theoretical considerations in applying benefit-cost and cost-effectiveness analysis to preventive dental programs. $J$. publ. Hlth. Dent. 44, 156-168, 1984.

9. Han U. K. Cost-effectiveness Analysis of Pit and Fissure Sealants (DMD thesis). Harvard University, Boston, 1986

10. Klein S. P., Bohannan H. M., Bell R. M., Disney J. A., Foch C. B. and Graves R. C. The cost and effectiveness of school-based preventive dental care. Am. J. publ. Hlth 75, 382-391, 1985.

11. Simonsen R. J. Retention and effectiveness of dental sealant after 15 years. J. Am. Dent. Assoc. 122, 34-42. 1991

12. Simonsen R. J. Retention and effectiveness of a single application of white sealant after 10 years. $J$. Am. Dent. Assoc. 115, 31-36, 1987.

13. Leverett D. H., Brenner C. M., Handelman S. L. and Iker H. P. Use of sealants in the prevention and early treatment of carious lesions: cost analysis. J. Am. Dent. Assoc. 106, 39-42, 1983.

14. Kuthy R. A., Branch L. G. and Clive J. M. First permanent molar restoration differences between those with and without dental sealants. J. Dent. Educ. 54, $653-660,1990$.

15. Joint BDA/DHSS Working Party. Fissure sealants. $\mathrm{Br}$. Dent. J. 161, 343-344, 1986.

16. Bureau of Economic and Behavioral Research. Dental fees charged by general practitioners and selected specialists in the United States, 1985. J. Am. Dent. Assoc. 113, 811-819, 1986.

17. Warner K. E. Issues in cost effectiveness in health care. J. publ. Hith Dent. 49, 272-278, 1989

18. Lawless J. F. Statistical Models and Methods for Lifetime Data. Wiley, New York, 1982.

19. Kleinbaum D. G., Kupper L. L. and Morgenstern H. Epidemiologic Research. Principles and Quantitative Methods. Van Nostrand Reinhold, New York, 1982. 
20. Howell E. M., Andrews R. M. and Gornick M. Longitudinal patterns of enrollment and expenditures for a Medicaid cohort. Hlth Care Financing Rev. 10, 71, 1988.

21. Eklund S. A. Factors affecting the cost of fissure sealants: a dental insurer's perspective. $J$. publ. Hlth
Dent. 46, 133-140, 1986.

22. Ripa L. W., Leske G. S. and Varma A. O. Longitudinal study of caries susceptibility of occlusal and proximal surfaces of first permanent molars. J. publ. Hlth Dent 48, 8-13, 1988 